\title{
20
}

\section{THE SOCIOCULTURAL CONTEXT OF CLIMATE CHANGE ADAPTATION IN AUSTRALIA, WITH A FOCUS ON HOT WEATHER}

\author{
CATHY BANWELL, JANE DIXON, HILARY BAMBRICK, \\ FERNE EDWARDS AND TORD KJELLSTROM
}

\section{Abstract}

In this chapter, we draw inspiration from Tony McMichael's research on the implications of climate change for human health and well-being and his exhortations to pay attention to the big picture. As a consequence, we use historical and contemporary materials to reflect on how Australia's cultural history has contributed to the development of our somewhat relaxed attitudes and practices in relation to increasingly hot weather and climate change. We consider the historical experiences of European settlers who arrived from the northern hemisphere with little understanding of hot weather and attempted to impose themselves on a foreign landscape. They developed a stoic approach to hot weather; something to be endured, if they were to survive. Over time, a more compromising attitude has developed as Australians gradually, and partially, adapt their clothing, behaviour, housing and location of residence to cope with the bodily discomforts of heat. Now they rely on techno-fixes, such as air conditioning, to manage hot weather, with unhelpful implications for climate change mitigation. Instead of relying on individual behaviour change, we nominate three policy domains where action is urgently required.

\section{Introduction}

Neither a complaint nor a boast, 'It's a scorcher!', is a common Australian summertime vernacular. In this chapter, we describe how cultural approaches that favour 'techno-fixes' at the household level have evolved in response 
to hot weather in Australia. We then proceed to describe them in terms of inadequate adaptive responses to climate change. We consider as a contextual narrative how these approaches have evolved from the historical experiences of European settlers who arrived from the northern hemisphere with little physical or psychological understanding of hot weather and attempted to impose themselves on a foreign landscape. They developed a stoic approach to hot weather; something to be endured, if they were to survive. Over time, a more compromising attitude has developed as Australians gradually, and partially, adapt their clothing, behaviour, housing and location of residence to cope with the bodily discomforts of heat.

Tony McMichael's research, over several decades, provided inspiration and guidance in analysing the nature of Australia's limited response to climate change science. First, he drew attention to the implications of climate change for human health and well-being and considered everyday responses to changed climatic conditions to be inadequate (McMichael, 1993, 2009). Second, he exhorted researchers not only to focus on proximate and measurable risk factors but also to consider their context, 'the big picture' (McMichael, 1999) - a point we return to in the conclusion.

In this chapter, we use historical and contemporary materials to provide context, reflecting on how Australia's cultural history influences our responses to future challenges posed by increasing numbers of heatwaves and droughts as the ramifications of a changing climate unfold. We argue that somewhat 'lazy' attitudes and related practices can be seen in our modern responses to hot weather; with unhelpful implications for climate change mitigation. Instead of relying on individual behaviour change, we nominate three policy domains where action is urgently required.

\section{The Impact of Heatwaves}

Typically during summer over much of Australia, consistently hot weather can last for several days, and even for weeks. Heatwaves (usually defined as daily maximum temperatures above $35^{\circ} \mathrm{C}$ for three or more consecutive days) cause significant human health impacts for the elderly, people on medication, the very young, the poor and Indigenous communities (Climate Commission, 2013). Certain respiratory and cardiovascular conditions increase the risk of morbidity and mortality during and immediately following very hot days (Vaneckova and Bambrick, 2013), particularly for people with a mental disorder or those who have at least one cardiac risk factor (Hansen et al., 2008a, 2008b).

According to the Australian Bureau of Meteorology and the Commonwealth Government (2009), heatwaves have actually accounted for more deaths in Australia than any other natural hazard. Findings from modelling studies that 
investigate the links between climate change and health (Hennessy et al., 2007; Kjellstrom and Weaver, 2009; McMichael et al., 2009) show that heatwaves are potentially one of the most damaging side effects of global warming, especially in a 'hot' country such as Australia, where the death rate from heatwaves may triple by 2100 in all Australian cities (Barlow, 2008).

With more frequent and intense heatwaves brought on by climate change, increasing numbers of Australians will be affected. This situation will require greater public health and medical attention, which, in turn, will be costly and resource-demanding. Heatwaves, especially as they become increasingly extreme, lead to loss of life and property through bushfires, and also place additional strain on infrastructure such as water, transport and electricity, causing a possible rise in social disturbance and instigating systemic economic flow-on effects to the retail industry, ecosystem services and tourism. For example, unexpected complications of the 2009 Melbourne heatwave included a full morgue, overworked hospital staff and limited resources, power loss to more than 6000 homes, heat-stricken wildlife, communication blockages and public transport breakdowns as railway tracks buckled (Progress Leader, 2009; Whittlesea Leader, 2009). The effects of extreme heat impact other species, too: in 2000, an unexpected impact of the Adelaide and Brisbane heatwaves was the substantial number of deaths of pigs, poultry and bees (Harris and Hooper, 2000; Nicholson, 2000).

While the effects of heat on mortality have now long been studied (e.g. Smoyer, 1998), there are still significant gaps in the study of the social experience of heat. Some research has been conducted into the social science of disasters (Klinenberg, 2002; Fothergill and Peek, 2004), but there has been little social research into the everyday aspects that contribute to such situations. This paucity of data could be attributed to research not yet published, a lack of social research into the experiences of hazard scenarios or the concentrated focus on the USA and Europe rather than on Australia or on developing countries.

Furthermore, the invisible and silent nature of heatwaves - as one of the most underrated and least-studied natural phenomena - needs to be unpacked because, once their initial impact is digested, they fade very quickly into the background. The deadly 1995 Chicago heatwave 'was forgotten as soon as the temperatures fell' (Klinenberg, 2002). Klinenberg's work is one of the few pieces of research to have examined the human experience and the sociocultural dimensions of heatwaves.

In essence, heatwaves cannot be categorised as a conventional environmental health hazard to be handled by public health departments. Their cumulative effect is to weaken life-support systems that underpin the survival of all species, requiring whole-of-government and whole-of-society responses. As the science of weather patterns becomes more settled, the research focus should shift to 
sociocultural studies as a basis both for preventive health campaigns (avoiding heatstroke and stress) and, more important, for strategies to strengthen engagement by civil society in policy advocacy to act to slow climate change.

\section{How Hot Weather has Shaped the Australian Psyche}

To the fierce sun of Australia, which tempers men as fire tempers steel; to the gracious sun of Australia, which makes nature teem with bounty; to the glowing sun of Australia, which warms the heart, enkindles the eye, ruddies the cheek, this in the tribute. (Fox, 1927)

The image of Australia is divided between pre- and post-European settlement - a world once inhabited solely by Aboriginal peoples suddenly transitioning in 1788 with the arrival of the fair-skinned British. It is not possible, in this short chapter, to do justice to the knowledge of, and adaptation to, the Australian climate demonstrated by Australia's first inhabitants, which was disrupted by the arrival of European settlers. Instead, we focus on the latter arrivals, who became enshrined in tales of the Aussie Bushman, Battler and the bronzed Sunbather. These cultural stereotypes were influenced strongly by the Australian landscape and climate, with the harsh, untamed, sun-drenched and isolating environment of the Outback contributing to the development of the Australian psyche as masculine, stoic, tough and quietly courageous. Hence, heat and the sun scorching the Earth, drying the ground and baking the skin is a consistent narrative contributing to, and sedimenting, the development of a particular Australian character. It is a narrative replete with health risks, as highlighted below.

\section{The Outback, the desert, the bush and the red heart}

The Australian bush, and the Outback, with an associated hot and harsh climate, was encountered by early settlers, and it helped form the contemporary Australian psyche. For well over a century, the Australian climate has been described as having irregular, uncertain and sporadic seasons in a threatening, alienating, endless and unrelenting landscape. Ranken (1874) pronounced the climate to be 'not only niggardly on the whole, it is a most capricious tyrant, destroying at uncertain intervals what it has reared in a few milder seasons'. Terminologies of drought differ between Europe and Australia, where the former defines drought as 'a period of a few days or weeks in which not a drop of rain falls', whereas in Australia drought becomes 'a period of months or years during which little rain falls and the country gets burnt up, grass and water disappear, crops become worthless and sheep and cattle die' (Sherratt, 2005, p. 6). In their first test, and 
as a matter of survival, European pioneers strove to adapt their agriculture and pastoralism to what was regarded as one of the driest continents on Earth. Even the lusher parts of Australia were drier and more climatically variable than most European landscapes, and the first settlers saw Australia in terms of opposites, pitting nature against civilised, wild versus tamed, opportunity versus anxiety and masculine versus feminine (Sherratt, 2005).

The obvious discomfort of Europeans on Australian soil led some to question if, indeed, they should be there at all. Foster Fraser believed that pioneer Australians 'lacked vim' and 'showed signs of having been drained by their climate' (cited in Walker, 2005, p. 94). Sunstroke, leading to madness for the colonial white male, became a prominent concern in the late 1800s. In the 1870s, 16 per cent of the male patients in the Yarra Bend asylum were diagnosed as 'sunstruck', awarding the Victorian colony the 'most unenviable position of being the maddest place in the world' (Foster, 1981). Boucher (2004) likens this malady within the medical discourse of the time as a consequence of white, middle-class, male, protestant bodies being out of place within the Australian environment and climate.

The sunstroke of Port Philip [causes] many deaths among the white population ... the thin skull of the European is unduly exposed to solar rays ... during the hot season in this climate ... Another distressing effect of Sunstroke, not infrequent in Victoria, is Insanity. (Mackin, 1856)

In view of this situation, it was suggested that, rather than trying to fight the climatic conditions, people from similarly tropical climes should be introduced to the north to populate the region. In response, the settlers of the time acted to make Australian conditions work for them, and hence began a campaign to embrace and celebrate the resilient persona of the Australian Battler. In one account, C. E. W. Bean described the qualities of the Australian character as forged in the battle against the elements, with progress won by an ongoing confrontation with nature. 'The Australian is always fighting something. In the bush it is drought, fires, unbroken horses and cattle' (Bean cited in Walker, 2005, p. 4). The ensuing typical Australian humour, too, was sculpted out of the harsh weather as dry and full of irony with 'a stoical acceptance of hardship; shrewd practicality; and sheer, sardonic bloody-mindedness' (Willey, 1988, p. 158). Portrayals of the Australian bush and its impact on new arrivals alternated from the realistic to the romantic, exemplified by its two key protagonists A. B. Banjo Patterson and Henry Lawson, with one describing Australia as 'benign and bountiful' and the other as a harsh destination that strips away civilisation for people to discover something within themselves (Radio National Hindsight, 2007). 
From Europeans trapped under a blazing sun in the dry Australian bush came a strong impulse to control nature, including the weather. The result was a series of scientific fixes, or 'silver bullets', including irrigation systems, dams, bores, the planting of forests and even the seeding of clouds (see Home, 2005). Rather than engaging with, or embedding themselves within, the Australian continent and climate, European colonialists tried to impose familiar features from their homelands (Lowe, 2005); such that D. H. Lawrence observed:

A grey, strange spirit, and the people that are here are not really here: only like ducks that swim on the surface of a lake. But the country has a fourth dimension and the white people float like shadows on the surface.

(D. H. Lawrence cited in Drew, 1994, p. 36)

This disconnect between the Australian landscape and its inhabitants - serving also to disconnect humans from nature - has created what Symons (2007), in his discussion of the Australian diet, describes as 'picnicking' atop Australia's surface. In a dramatic break from their previous lived experience, newly arrived Europeans could dispatch with a peasant existence, which involved growing food for themselves and a small number of households. They leapfrogged to becoming farmers and pastoralists, producing agriculture on a large scale, with the help of irrigation and later with fossil fuel inputs, 'riding the sheep's back' to prosperity for themselves and their nation. In so doing, they contributed to feeding their colonial masters, and to the present situation where pastoral agriculture makes a major contribution to Australia's greenhouse carbon and methane emissions a topic central to Tony McMichael's research on the multiple links between food systems, climate change and population health (McMichael et al., 2007).

\section{City life, beach and sun worship}

Despite the Outback mythology, Australia is one of the most urbanised countries in the world, with 89 per cent of its population living along the coast in or near its six state capital cities (Bambrick et al., 2011). Therefore, city, not desert, has arguably become most representative of the Australian identity. As more Australians have moved from the bush to urban centres, the stoic Aussie Battler has become supplanted in city settings. Traditionally equated with conquering Outback conditions, the Aussie Battler is now more likely to be seen lying prone on a city or peri-urban beach after a week spent in the office or factory.

Indeed, visiting an Australian beach for health, relaxation and to escape the heat forms another rich vein in the Australian psyche. The Australian coast has a long history of habitation, serving as a healthy holiday destination since the era of the First Settlers, where the combination of sea breeze and sun acted as a cure-all and as a place for renewal. At the beach, the Australian heat was 
seen as energising, and the 'new Australians' ability to adapt and endure beach conditions made them bolder, adventurous and more resilient' (Walker, 2005, p. 97). The sun as a source of pleasure and revitalisation became fully realised in the surf culture that flourished on waves of consumerism and bikini contests in the 1920s and 1930s. The beach, and surfing in particular, became the urban equivalent to Australia's frontier, and the surf lifesaver became the new urban hero after the war. Maxwell (cited in Huntsman, 2001, p. 199) sums up lifesaving clubs as fostering 'a spirit of selflessness, of chivalry, such as is found in no other sporting movement in all the world today, not counting the cost when a life is for the saving'. Surfing heroics were also well expressed by Fox:

Australian surfing is not a matter of tip-toeing over wet sands and through shallow pools. It is standing up to great breakers of ocean water, champagned to foam as they break their crests; and giving to the meeting body mighty thumps, massaging and bracing the muscles delightfully.

(Fox, 1927, pp. 101-2)

Rodwell (1999) describes this surf culture in terms of eugenics, with the sun's rays improving the physical attributes of both men and women. Similarly, Professor H. G. Chapman, in his 1928 address at the Australasian Association for the Advancement of Science Congress, calls Australians 'sun-worshippers' and states that 'not only in height, weight and build, but also in chemical composition and in nutrition was the Australian changing from his British forefathers. One factor that acted all over Australia in producing persons more fitted to live in Australia was sunshine' (Chapman, 1928). It was almost half a century later before it was recognised that the sun produced adverse health effects, such as skin cancers, with McMichael again providing early calls to examine the links between these health outcomes and climate change (McMichael, 1993).

\section{Australian Adaptations to Hot Weather}

Over the two centuries of European settlement, Australians have adapted their dwellings to cope with hot weather, using three particular strategies; the veranda, the air conditioner and water-thirsty gardens. The ubiquitous Australian veranda, adopted from British India, symbolises Australians' relationship to place, weather and their own cultural ambivalence towards heat. Drew (1994) uses the veranda as a metaphor to analyse the implications on the Australian identity for living on the edge or periphery of the continent looking out to sea. The pattern of space created by the veranda and repeated by verandaways (a passage of linked verandas from adjoining buildings) reveals 'how Australians have responded to the physical presence of Australia' (Drew, 1994, p. 11). It represents a transitional zone between indoor and outdoor living. 
The veranda was 'tacked on' to existing European-style buildings from the time of colonisation, providing a lived-in passage that also acted as a protective barrier against harsh sun and rain while harnessing sea breezes. Australians, in fact, have revealed a preference to 'live outside their homes' (Huntsman, 2001, p. 182), reflected by the cultural value they attach to active outdoor pursuits of sport, the beach and the outdoor kitchen in the form of the barbecue. Rather than internalising their moral or intellectual dilemmas, the Aussie Battler has been described as getting 'on with the business of surviving'. Philip Drew, in his book, The Coast Dwellers, expresses this national propensity to the great outdoors as 'Australia is a verandah country inhabited by a verandah people' (Drew, 1994, p. 21).

Supplanting this enculturated 'fringe behaviour' are new technologies to replace older approaches to climate adaptation. The two most common are home air conditioning and climate-controlled cars. Modern houses are being designed without eves or verandas, and may have sealed windows to suit air conditioning better. Before air conditioning, people used their verandas. They 'created opportunities for casual observations and social exchange, and people would eat, play and sleep outside' (Shove, 2003, p. 45). In contrast, air conditioning has privatised comfort, drawing people from their social networks on the verandas back inside their homes. People would also employ their own techniques to regulate the temperature, such as a liberal use of water for cooling: whether a bowl of water in front of a window or old fan, damp cloths on the back of the neck, garden sprinklers or sitting in a water-filled container. They would evaluate personally what they considered to be comfortable, displaying an achievement of personal skill and climatic awareness (Shove, 2003).

The arrival of new technologies has allowed modern Australian families to adapt to heat in different, albeit more climate damaging, ways. They can turn on air conditioning at home or jump into climate-controlled cars to drive to cooler destinations, such as the beach, country streams, waterholes or rivers, or to hide out in air-conditioned shopping malls, cinemas or libraries. They can call up fast-food deliveries instead of home-meal preparation on the hottest of days, further increasing the consumption of fossil fuels and their associated emissions (Banwell et al., 2012). Stoicism has given way to energy consumption in the name of comfort, but both are lazy responses and have the same negative impact on the climate. As Hamilton has noted, modern Australians' desire to climate-proof their lives

is an extension of human attempts to control the natural world and its impacts on us, and this is transforming our psyches in profound ways. ... we harden ourselves against the effects of Nature's unexpected forces, and our relationship to the natural world is transformed. (Hamilton, 2005, p. 191) 
Rather than supporting stronger and more costly household energy- and water-saving measures, Australians have recently voted in a government that campaigned on abolishing the Department of Climate Change and on repealing carbon pricing in favour of so-called 'direct action' on the climate. While it is still unclear what this means, it appears to signal a voluntary code to deal with non-renewable energy production and consumption. It frames the problems of the environment and climate in terms of negotiable, and easy, solutions. It situates the national response in terms of the national psyche, as forged through a relative abundance of natural resources and an easy-going national psyche. This lazy and laissez-faire approach was evidenced by the behaviour of citizens during the 2009 Melbourne heatwave in the suburb of Boroondara. The four public swimming pools increased in use by 90 per cent compared to the same time the previous year, and trips to aquatic centres proved very popular (Rollins, 1997; Progress Leader, 2009). Likewise, a DVD shop manager said his store was extremely busy as customers stocked up on videos and DVDs for the hot weather (Whittlesea Leader, 2009). Others spent their hot days purchasing acquired technologies and tastes to keep them cool - air conditioners, fans and other cooling appliances 'walked out the door' as stores experienced a spike in sales of ice, water, ice cream and cold drinks, such as beer (Norrie, 2002; Chambers and Minchin, 2003; Illawarra Mercury, 2003).

Yet, these adaptations in no way address the problem of heat and heat-related illness and death. The extreme case of possible statewide energy failure occurred in summer 2004, in Western Australia, leading the Western Power company to ban the use of energy-hungry air conditioners in homes and offices, effectively ordering a shutdown of all industry. To endorse this behaviour change, Western Power threatened to fine residents $\mathrm{A} \$ 1000$ and businesses $\mathrm{A} \$ 10,000$ for non-compliance (Martin et al., 2004). Nevertheless, the following year, The Australian reported that 'more than 100,000 new household air conditioners have been installed in Western Australia' (Wilson, 2005, p. 2).

There is a final irony to the Australian laconic approach to climate change adaptation: 'move away'. Heat can be an important factor leading to some people moving to entirely new locations. Australians who relocate to more temperate climes include those who 'downshift', 'sea or tree change' or, specifically for the elderly, become part of the 'grey nomad' phenomenon, escaping the cold in winter and the heat in summer. In The Big Shift, Salt documents a sizeable population shift from the cities to non-metropolitan coastal towns (Salt, 2001). According to 2001 census data, 3.9 million people live in provincial coastal Australia with allegiance to neither city nor bush (Salt, 2001).

These sea-changers consist predominantly of retirees, alternative lifestylers, people who conduct business over the Internet, people with low incomes who cannot afford appropriate housing in city centres, periodic tourists and gentrifiers 
(people who buy and renovate houses to sell for profit). Their motivations are varied, but the benefits of temperate weather are certainly factored into these relocations (Murphy, 2002). The recognition of this population shift and corresponding impact on coastal communities led to the national government establishment in 2004 of a National Sea Change Taskforce to represent the interests of coastal councils and communities experiencing the effects of rapid growth and development (Gurran and Blakely, 2007). Since then, these same councils have been alerted to the potential loss of coastline due to sea level rise associated with climate change, with some state governments overriding local government planning permissions for development on their most valuable ocean-hugging lands.

\section{Conclusions}

The Australian character has been shaped by myriad landscapes morphing from the Aussie (rural) Battler to sportsman to surfer to lifesaver, all based on inhabiting (adapting to) and taming the natural environment and weather 'elements'. As rising tides consume Australia's shorelines and as increasingly erratic weather tears at the landscape, the Australian island will become hotter, drier and smaller. The historical influences of the stoic Australian psyche may foster a more recent state of denial or laziness, slowing the uptake of green technologies, policies and action, even as Australians become increasingly reliant on air conditioning to micromanage their hot weather. Whether Australians, as The Climate Institute suggests they should in their paper, Towards a Climate Strategy for Australian Agriculture (2009, p. 5), take hot weather seriously enough to transit to a low-carbon country currently appears an increasingly doubtful proposition.

Indeed, climate change has become a more, rather than less, politically contested area in Australia over the last decade, contributing to the need to understand what McMichael refers to as the 'big picture'. And, the 'big picture' embraces the cultural and social contexts that have influenced, and continue to influence, experiences and understandings of the impact of climate change. If we are correct about the weight of history, then leaving the response to heatwaves to individual behaviour change is self-defeating. What we propose are three 'lifestyle' policy domains that urgently require action because they change the calculus of choices available. They are higher non-renewable energy and water costs; built environment designs that are less reliant on electric air conditioners and more reliant on urban greening for cooling; and mass transit options to make car travel less attractive. Each of these policy alternatives has equity considerations and will require increases to minimum wages and pensions to offset the impacts on lower-income households. However, given that lower 
socio-economic groups are more exposed to heat effects, the equity dimensions to climate change policy cannot be avoided. We are not arguing that community lifestyle change is adequate to the task of slowing climate change and we endorse non-voluntary action to change the energy, materials and water-use behaviour of Australian businesses and governments. However, whole-of-community lifestyle change is an increasingly urgent task, as the growing impact of climate change on Australian weather conditions will generate enough floods, droughts, fires and heatwaves to test even the most resilient of Australians.

\section{References}

Bambrick, H.J., Capon, A.G., Barnett, G.B., Beaty, R.M. \& Burton, A.J. 2011. Climate change and health in the urban environment: adaptation opportunities in Australian cities. Asia Pacific Journal of Public Health 23, 67-79.

Banwell, C., Dixon, J., Bambrick, H., Edwards, F., Kjellstrom, T. 2012. Socio-cultural reflections on heat in Australia with implications for health and climate change adaptation. Global Health Action 5, 19277, dx.doi. org/10.3402/gha.v5i0.19277.

Barlow, G. 2008. Nurses feel impact of climate change. Australian Nursing Review 15, 24-7.

Boucher, L. 2004 Masculinity gone mad: settler colonialism, medical discourse and the white body in late nineteenth-century Victoria. Lillith 13, 51-67.

Chambers, T. \& Minchin, L. 2003. How the heat is taking its toll (and how we're coping). The Sunday Age, Melbourne, VIC, 2 February 2003.

Chapman, H.G. 1928. Science Congress: Sun-Worshippers: The Typical Australian. Address by Professor H. G. Chapman.

Climate Commission 2011. The Critical Decade: Climate Change and Health www.climatecouncil.org.au/uploads/1bb6887d6f8cacd5d844fc30b0857931. pdf, accessed 4 July 2015.

Commonwealth Government. 2009 Protecting human health and safety during severe and extreme heat events. www.pwc.com.au/industry/government/ assets/extreme-heat-events-novll.pdf.

Drew, P. 1994. The Coast Dwellers. Penguin Books Australia, Ringwood, VIC, Australia. 
Foster, S.G. 1981. Imperfect Victorians: insanity in Victoria in 1888, Australia 1888. Bulletin, 8, 97-116.

Fothergill, A. \& Peek, L. 2004. Poverty and disasters in the United States: a review of recent sociological findings. Natural Hazards 32, 89-110.

Fox, F. 1927. Australia. A. \& C. Black Ltd, London, UK.

Gurran, N. \& Blakely, E. 2007. Suffer a sea change? Contrasting perspectives towards urban policy and migration in coastal Australia. Australian Geographer 38, 113-31.

Hamilton, C. 2005. Social psychology of climate change. In: Sherratt, T., Griffith, T. \& Robin, L. (eds) A Change in the Weather: Climate and Culture in Australia. National Museum of Australia Press, Canberra, ACT, Australia, 187-95.

Hansen, A., Bi, P., Nitschke, M., Ryan, P., Pisaniello, D. \& Tucker, G. 2008 a. The effect of heat waves on mental health in a temperate Australian city. Environmental Health Perspectives 116, 1369-75.

Hansen, A., Bi, P., Ryan, P., Nitschke, M., Pisaniello, D. \& Tucker, G. 2008b. The effect of heat waves on hospital admissions for renal disease in a temperate city of Australia. International Journal of Epidemiology 37, 1359-65.

Harris, S. \& Hooper, B. 2000. Surviving in a sunburnt country. Adelaide Advertiser, SA, 12 January 2000, 19.

Hennessy, K., Fitzharris, B., Bates, N., Harvey, S., Howden, L., Hughes, J., et al. 2007. Chapter 11. Australia and New Zealand. Climate Change 2007: Impacts, Adaptation and Vulnerability. Contribution of Working Group II to the Fourth Assessment. Report of the Intergovernmental Panel on Climate Change. 50740. IPCC, Geneva, Switzerland.

Home, R.W. 2005. Rainmaking in CSIRO: the science and politicis of climate modification. In: Sharratt, T., Griffith, T. \& Robin, L. (eds) A Change in the Weather: Climate and Culture in Australia. National Museum of Australia Press, Canberra, Australia, 66-79.

Huntsman, L. 2001 Sand in our Souls. The Beach in Australian History. Melbourne University Press, Melbourne, Australia.

Illawarra Mercury, Wollongong, NSW. 2003. Perth roasts in heat wave, 11 March 2003. 
Kjellstrom, T. \& Weaver, H. 2009. Climate change and health: impacts, vulnerability, adaptation and mitigation. New South Wales Public Health Bulletin 20, 5-9.

Klinenberg, E. 2002. Heat Wave: A Social Autopsy of Disaster in Chicago. University of Chicago Press, Chicago, Illinois, USA.

Lowe, I. 2005. Solar energy. In: Sherratt, T., Griffith, T. \& Robin, L. (eds) A Change in the Weather: Climate and Culture in Australia. National Museum of Australia Press, Canberra, Australia, 116-25.

Mackin, C.T. 1856. Sunstroke or coup de soleil: its causes, consequences and pathology. Australian Medical Journal 5, 85-6.

McMichael, A.J. 1993. Planetary Overload: Global Environmental Change and the Health of the Human Species. Cambridge University Press, Cambridge, UK.

McMichael, A.J. 1999. Prisoners of the proximate: loosening the constraints on epidemiology in an age of change American Journal of Epidemiology 149, 887-97.

McMichael, A.J., Powles, J., Butler, C.D., Uauy, R.. 2007. Food, livestock production, energy, climate change, and health. The Lancet 370, 1253-63.

McMichael, A.J., Neira, M., Bertollini, R., Campbell-Lendrum, D. \& Hales, S. 2009. Climate change: a time of need and opportunity for the health sector. The Lancet 374, 2123-5.

Martin, B., Pennels, S. \& Adshead, G. 2004. WA faces shutdown in new power crises - power orders what you can't do. The West Australian, 18 February 2004 .

Murphy, P. 2002. Sea change: re-inventing rural and regional Australia. Transformations 2, 1-12.

Nicholson, S. 2000. Heatwave plays havoc with lives. The Australian, 29 January 2000, 44.

Norrie, J. 2002. Heatwave has valley sizzling. Newcastle Herald, NSW, 20 March 2002.

Progress Leader, VIC. 2009. Heat wave pushes people's temperatures up. 3 February 2009.

Radio National Hindsight 2007. The Australian Landscape - The Long Hot Summer - Heat. Directed by Radio National Hindsight. 
Ranken, W.H.L. 1874. The Dominion of Australia: An Account of its Foundation. Chapman and Hall, London, UK.

Rodwell, G. 1999. The sense of victorious struggle; the eugenic dynamic in Australian popular surf-culture, 1900-1950. Journal of Australian Studies 23, 56-63.

Rollins, A. 1997. Last time it was this hot, ball gowns were beachwear. Sunday Age, 23 February, 1997.

Salt, B. 2001. The Big Shift: Welcome to the Third Australian Culture. Hardie Grant, Melbourne, VIC, Australia.

Sherratt, T. 2005. Human elements. In: Sherratt, T., Griffith, T. \& Robin, L. (eds) A Change in the Weather: Climate and Culture in Australia. National Museum of Australia Press, Canberra, Australia, 1-17.

Shove, E. 2003. Comfort, Cleanliness and Convenience. The Social Organisation of Normality. Berg, Oxford, UK \& New York, NY, USA.

Smoyer, K. 1998. A comparative analysis of heat waves and associated mortality in St Louis, Missouri - 1980 and 1995. International Journal of Biometeorology $42,44-50$.

Symons, M. 2007. One Continuous Picnic. A Gastronomic History of Australia, 2nd edition. Melbourne University Press, Melbourne, VIC, Australia.

The Climate Change Institute 2009 Towards a climate strategy for Australian agriculture www.climateinstitute.org.au/verve/_resources/towards_climate_ friendly_ag_policy_brief.pdf.

Vaneckova, P. \& Bambrick, H. 2013. Cause-specific hospital admissions on hot days in Sydney, Australia. PLoS ONE, doi:10.1371/journal.pone.0055459.

Walker, D. 2005. The curse of the tropics. In: Sherratt, T., Griffith, T. \& Robin, L. (eds) A Change in the Weather: Climate and Culture in Australia. National Museum of Australia Press, Canberra, ACT, Australia, 92-101.

Whittlesea Leader, Preston, VIC. 2009. City wilts in heat. 4 February 2009.

Willey, K. 1988. A hard, dry humour for a hard, dry land. In: Burgmann, V. \& Lee, J. (eds) Constructing a Culture. A People's History of Australia since 1788. McPhee Gribble Publisher, Fitzroy, VIC, Australia, 156-69.

Wilson, N. 2005. Aircon boom a power risk for Gallop. The Australian, 11 January 2005. 
This text is taken from Health of People, Places And Planet:

Reflections based on Tony McMichael's four decades of contribution to epidemiological understanding, edited by Colin D. Butler, Jane Dixon and Anthony G. Capon, published 2015 by ANU Press, The Australian National University, Canberra, Australia. 